\title{
Coronal Discoloration Related to Bioceramic and Mineral Trioxide Aggregate Coronal Barrier in Non-vital Mature Teeth Undergoing Regenerative Endodontic Procedures
}

\author{
Mohammad Yaman Seirawan ${ }^{1}$, Kinda Layous $^{2}$, Mohammad Kinan Seirawan $^{3}$, Mazen Doumani ${ }^{4}$
}

\begin{abstract}
Objectives: This study aimed to compare the coronal discoloration related to the application of two coronal sealing materials: Bioceramic (BC) root repair material (RRM) putty and mineral trioxide aggregate (MTA).

Materials and methods: A total of 16 patients (divided into two subgroups, each one included 8 patients) had undergone regenerative endodontic procedures (REPs). Disinfecting the canals was achieved by the application of the double-antibiotic paste (DAP) "metronidazole and ciprofloxacin" to exclude minocycline discoloration effect; after 3 weeks, the medicament was removed, apical bleeding was induced till the formation of blood clot in the root canal, and then a coronal sealing was created. Bioceramic RRM putty was used in eight patients, while gold standard "MTA" was used in another eight patients. Finally, resin modified glass ionomer (RMGI) was applied followed with resin composite matching the shade of the treated teeth. Shades were measured immediately after procedures and through organized follow-up $(3,6,9$, and 12 months). Data were collected according to Commission International de l'Eclairage (CIE-LAB) and then $\triangle E$ values were calculated. A two-way statistical analysis of variance was performed depending on Student's $t$ and Chi-square tests at $95 \%(p=0.05)$.

Results: Coronal discoloration accompanied with MTA was clinically perceptible ( $\triangle E>3.3$ ) through all periods. Coronal discoloration was slightly recognized in the BC group. However, there was no significant difference between the used two materials through studied periods $(p>0.05)$. There was incrementally increasing of discoloration through sequential organized follow-up periods.

Conclusion: As a result of this study, BC RRM putty could be a good alternative material to MTA through REPs.

Clinical significance: Pulp REPs are predictable therapies, but discoloration is still considered as a one of the most unfavorable complications; so, this study highlights on this outcome to obviate it.

Keywords: Bioceramic, Discoloration, Mineral trioxide aggregate, Regenerative endodontic procedures.

World Journal of Dentistry (2020): 10.5005/jp-journals-10015-1698
\end{abstract}

\section{INTRODUCTION}

Root canal therapy is a traditional method used to remove pulp tissue and replace it by inorganic materials. Therefore, there is a need to regain vitality of the dental pulp to save teeth as long as possible, where tissue engineering could lead to reproduce as same as original pulp tissue with similar morphology and function. ${ }^{1}$ Pulp regenerative endodontic procedures (REPs) are based on three basic elements, namely stem cells, scaffolds, and growth factors, and require two conditions, such as effective disinfection and apical foramen with proper size. ${ }^{2}$ Regenerative endodontic procedures prolong on two visits, where the canal would be filled with induced blood clot after efficient disinfection with a medicament of calcium hydroxide or triple antibiotic paste (TAP) after mechanical preparation accompanied by sodium hypochlorite. ${ }^{3}$ Non-vital mature teeth with/without apical periodontitis are traditionally treated with nonsurgical root canal therapy which has predictable outcomes. Recently, successful treatments of mature necrotic teeth with/without apical periodontitis were obtained with REPs, and the results were considered positive if therapies led to elimination of clinical signs/symptoms and healing of apical periodontitis. ${ }^{4,5}$ Despite a high success rate of REPs with regard to resolving signs and symptoms of disease and periodontal healing, discoloration is still considered one of the most important unfavorable complications. ${ }^{6,7}$ There is certainly a relationship between discoloration and minocycline used in TAP., 8 .9 Therefore, the use of double-antibiotic paste (DAP) "without minocycline" was
1,2Department of Restorative and Endodontics, Faculty of Dentistry, University of Damascus, Damascus, Syria

${ }^{3}$ Department of Removable Prosthodontics, Faculty of Dentistry, University of Damascus, Damascus, Syria; Department of Prosthetic Dental Sciences, Al-Farabi College for Dentistry and Nursing, Riyadh, Saudi Arabia

${ }^{4}$ Department of Restorative Dental Sciences, Al-Farabi College for Dentistry and Nursing, Riyadh, Saudi Arabia

Corresponding Author: Mohammad Yaman Seirawan, Department of Restorative and Endodontics, Faculty of Dentistry, University of Damascus, Damascus, Syria, Phone: +963 999520717, e-mail: Yamansr@hotmail.com

How to cite this article: Seirawan MY, Layous K, Seirawan MK, et al. Coronal Discoloration Related to Bioceramic and Mineral Trioxide Aggregate Coronal Barrier in Non-vital Mature Teeth Undergoing Regenerative Endodontic Procedures. World J Dent 2020;11(1):52-60.

Source of support: Nil

Conflict of interest: None

suggested as an alternative medicament because DAP discoloration is not perceptible by the human eye. ${ }^{10}$ Mineral trioxide aggregate is a calcium silicate-based reparative material used in REPs as a coronal barrier, it is characterized by biocompatibility, marginal sealing, and biological properties, but one of the most unfavorable

(c) The Author(s). 2020 Open Access This article is distributed under the terms of the Creative Commons Attribution 4.0 International License (https://creativecommons. org/licenses/by-nc/4.0/), which permits unrestricted use, distribution, and non-commercial reproduction in any medium, provided you give appropriate credit to the original author(s) and the source, provide a link to the Creative Commons license, and indicate if changes were made. The Creative Commons Public Domain Dedication waiver (http://creativecommons.org/publicdomain/zero/1.0/) applies to the data made available in this article, unless otherwise stated. 
properties is discoloration involvement. ${ }^{11}$ Discoloration is probably attributed to the coronal sealing material; calcium silicate is the standard material used in this purpose, and mineral trioxide aggregate (MTA) is the most type of calcium silicate which is used in REPs as a gold standard material. ${ }^{12}$ Other types of calcium silicate like Biodentine, bioceramic (BC) root repair material (RRM) putty, and calcium-enriched mixture cement are also used in REPs. ${ }^{13}$ Although some literature reviews showed limited staining potential of some calcium silicate materials on dental tissue, other reviews showed high perceptible discoloration related to calcium silicate materials. However, the incidence of discoloration was due to oxidation of the metal elements like iron, bismuth, or manganese which are ingredients included in the calcium silicate materials. ${ }^{14}$ Ethylenediaminetetraacetic acid (EDTA) has limited evidence on discoloration on dental tissues and is recommended as a final irrigation solution in REPs according to American Association of Endodontics (AAE). ${ }^{15}$ The blood clot is the most popular matrix used in REPs; ${ }^{12}$ when accumulated hemoglobin of blood undergo metabolism, hematin molecules precipitate in dentin tubules and lead to staining, ${ }^{16}$ as well as possibility of calcium silicate material discoloration when they were in contact with blood. ${ }^{17}$ There are many tricks to prevent or at least diminish discoloration in REPs, like place the coronal barrier "coronal sealing material" more apically, and this region of tooth structure will be covered by bone or gingiva. A double layer of dentin bonding agent (DBA) is recommended in the access cavity, to diminish of the penetration of tinctorial components into dentinal tubules to avoid discoloration. ${ }^{8,18}$ Nevertheless, the application of DBA does not prevent the clinically perceptible coronal color change completely, but it reduces the tooth discoloration significantly. ${ }^{19}$ Therefore, the aim of this clinical study was to compare incidence of discoloration after REPs with two different materials for coronal sealing: the first material is MTA, and the second one is BC RRM putty to perceive potential role of coronal sealing material in posttreatment discoloration.

\section{Materials and Methods}

This study was conducted in the dental clinics of faculty of dentistry in Damascus University for 14 months in total (from August 2018 to October 2019). It involved 16 patients who have a non-vital tooth (by traumatic/carious reasons) with single root canal with/without periodontitis disease. Regardless of the location (superior/inferior), the regenerative treatment decision was taken, and the patients were informed by full details, and consents were taken regard special clear ethical approval.

All patients had undergone similar procedures under rubber dam isolation starting from straight access cavity. Then, instrumentation with ProTaper ${ }^{\circledR}$ Universal till F3 (Dentsply Maillefer, Switzerland), apical manual enlargement to size of $0.60,{ }^{5}$ synchronizing with disinfection of canals by sodium hypochlorite $1.5 \%(\mathrm{NaOCl} ; 20 \mathrm{~mL} /$ canal, 5 minutes), followed by saline and then 17\% EDTA (20 mL/ canal, 5 minutes) according to $A A E,{ }^{15}$ and final irrigation by saline and EDTA were used to remove a smear layer from dentinal walls. Then, the canals were dried with sterilized paper points. Doubleantibiotic paste (metronidazole and ciprofloxacin $0.25 \mathrm{mg}$ of each drug) mixed with distilled water $(0.50 \mathrm{~mL})$ to a concentration of 1 $\mathrm{mg} / \mathrm{mL}$ as a temporary medicament was inserted into the canal and ensured to be below cementum-enamel junction (CEJ) ${ }^{20}$ and then access sealing was done by glass ionomer (Fuji IX GP; GC, Japan). In the second visit (after 3 weeks), every patient was checked up with exclusion of any signs/symptoms and then the medicament was flushed out by copious irrigation by saline and then $20 \mathrm{~mL}$ of $17 \%$ EDTA accompanied by ultrasonic activation to ensure the removal of medicament as much as possible. Then, bleeding was evoked by introducing precurved \#15 K file $3 \mathrm{~mm}$ beyond the apex with motion of clockwise/contraclockwise; after the bleeding fulfillment till the orifice of canals and waiting about 10-15 minutes, the blood clot was formed, and its stability was checked at the CEJ level or lower than that. All patients had undergone the same previous steps till the coronal sealing step where they were divided into an experimental group and a control group ( $n=8$ teeth per group).The control group had white MTA (ProRoot; Dentsply Tulsa, USA) as the coronal barrier material followed by resin-modified glass ionomer (lonoseal; VOCO, Germany) and resin composite filling (Filtek Z250 XT; 3M ESPE, USA) (Figs 1 and 2), whereas the experimental group had BC RRM putty (TotalFill; FKG, Switzerland) as the coronal barrier followed by the same aforementioned materials (Figs 3 and 4). VITA Easyshade ${ }^{\circledR}$ Advance 4.0 (VITA, Germany) was calibrated before using each time and then it is used to measure the shade in the central region of the buccal surface of each treated tooth twice at each time immediately after the procedures and through organized follow-up visits $(3,6,9$, and 12 months), and the mean of the two measurements was calculated. Data were collected according to CIE-LAB (1976), which is a uniform color scale designed to perceive accurate colors, where $L, a$, and $b$ are color values; $\left(L^{*}\right)$ indicates to value of lightness or darkness on a scale from black (0) to white (100); $\left(a^{*}\right)$ indicates to progression from red $\left(+80 a^{*}\right)$ to green $\left(80 a^{*}\right)$; and $\left(b^{*}\right)$ indicates to progression from yellow $\left(+80 b^{*}\right)$ to blue $\left(80 b^{*}\right)$. The color difference is calculated by the following equation:
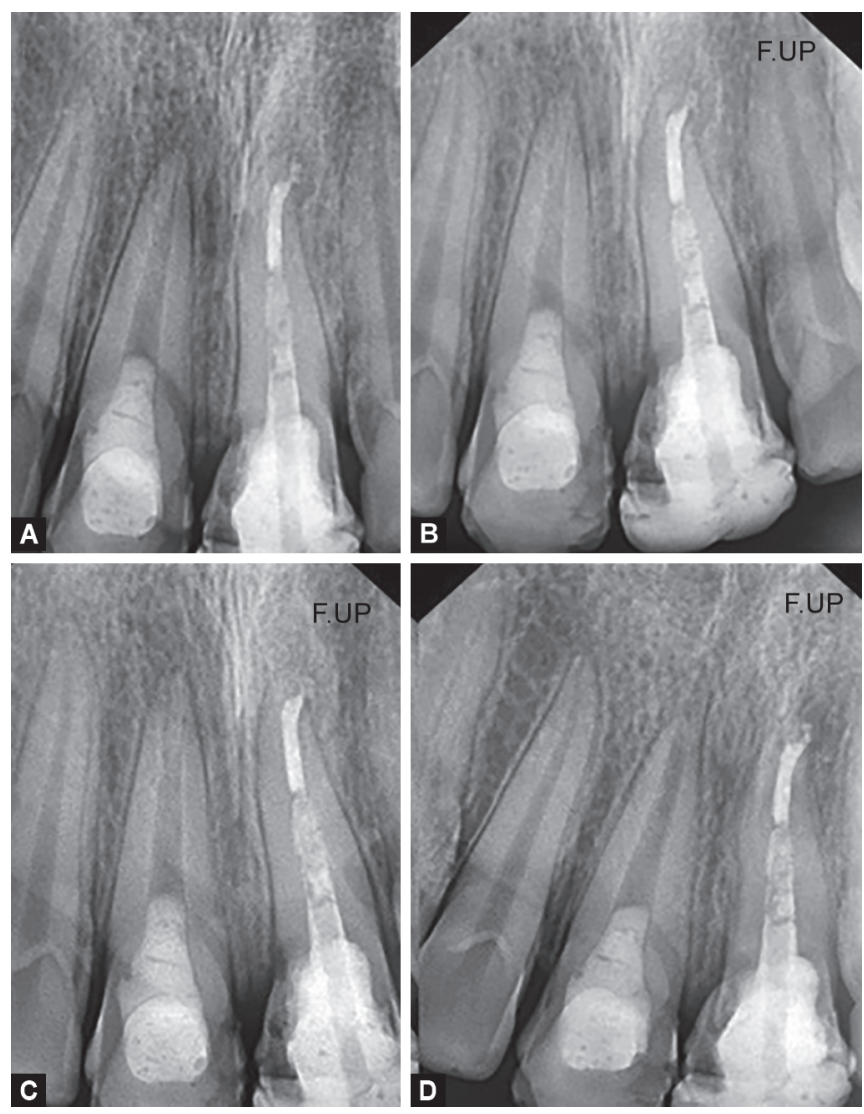

Figs $1 A$ to $D$ : Mineral trioxide aggregate as a coronal barrier on the upper right central incisor: (A) After application; (B) After 3 months; (C) After 6 months with good healing; (D) After 9 months with superior healing 

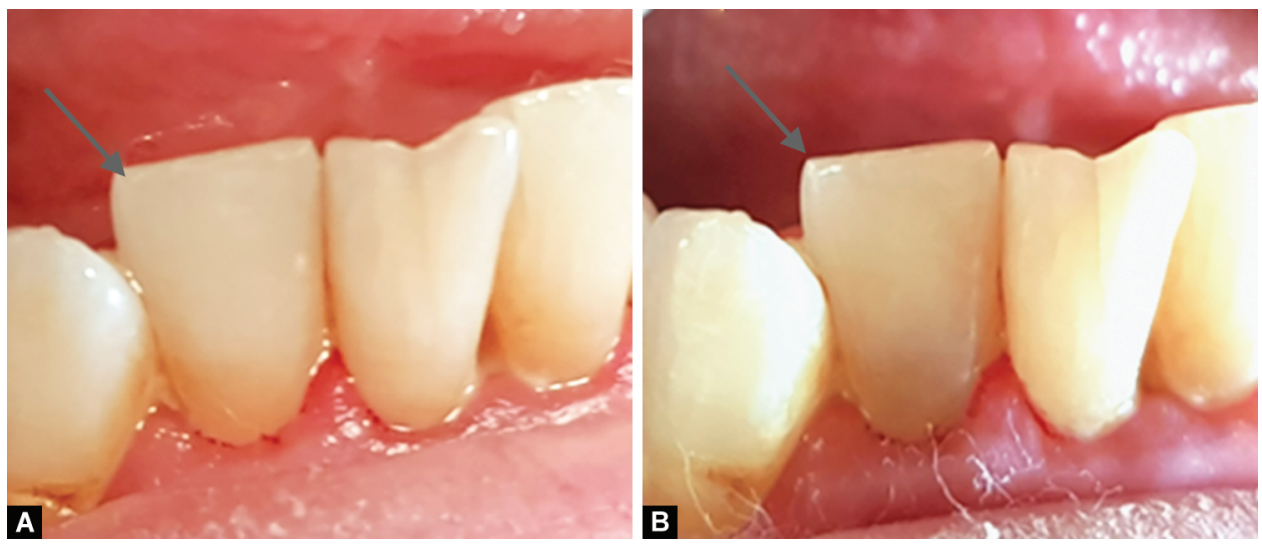

Figs 2A to B: Discoloration after application of mineral trioxide aggregate as a coronal barrier on the lower right lateral incisor: (A) After application; (B) After 6 months with noticeable discoloration
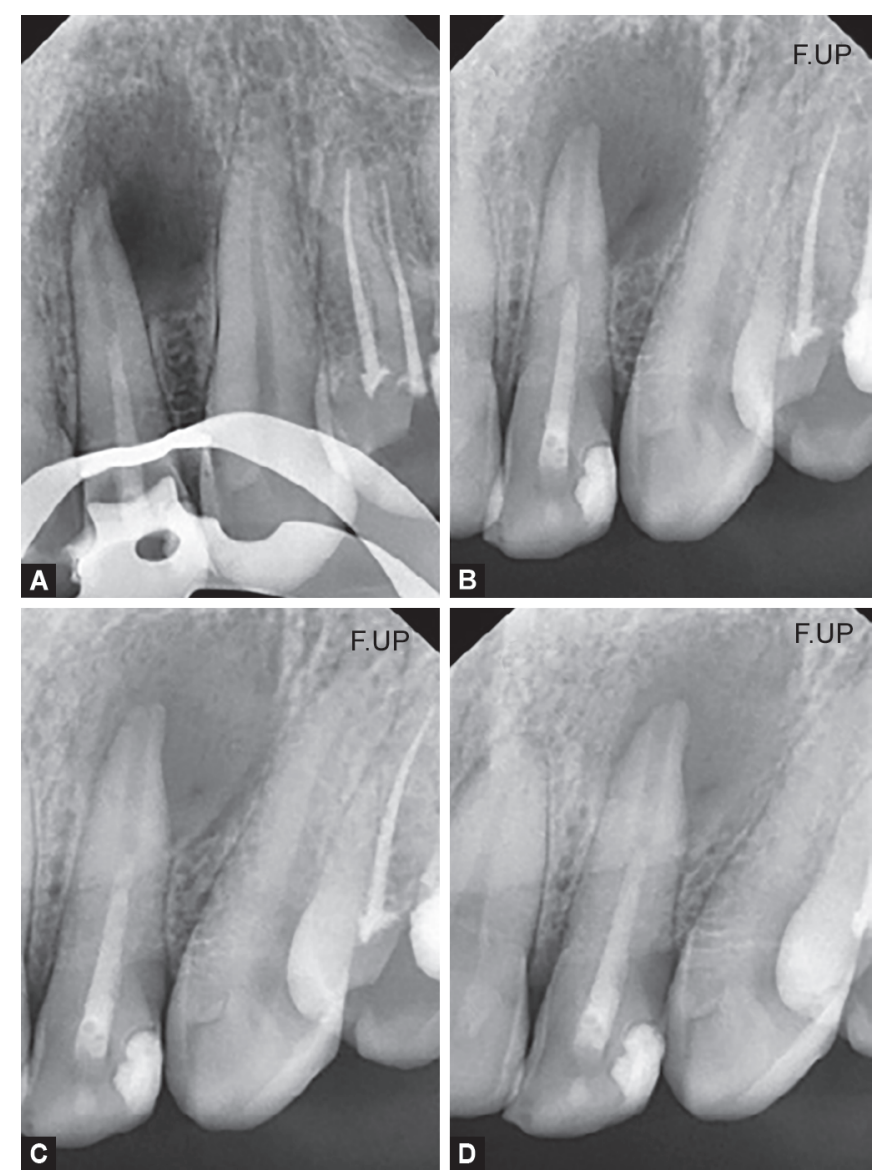

Figs $3 A$ to D: Bioceramic as a coronal barrier on the upper left lateral incisor: (A) After application directly; (B) After 3 months with no difference; (C) After 6 months with preliminary healing indication; (D) After 9 months with superior healing

$$
\Delta E=\sqrt{(\Delta L)^{2}+(\Delta A)^{2}+(\Delta B)^{2}}
$$

Or

$$
\Delta E=\sqrt{\left(L_{i}-L_{0}^{*}\right)^{2}+\left(a_{i}-a_{0}{ }^{*}\right)^{2}+\left(b_{i}-b_{0}^{*}\right)^{2}}
$$

Then, $\Delta E$ values were calculated and compared between intervals in the same groups and between two groups from each other.

$\Delta E$ discoloration less than 3.3 is considered not perceptible (no discoloration effect), and $\Delta E$ discoloration equal/over 3.3 is considered perceptible (discoloration effect). ${ }^{21,22}$

\section{Statistical Analysis}

SPSS software was used to evaluate data (PASW Statistics 13; SPSS, Inc., Chicago, IL, USA), to evaluate the role of the coronal barrier type on discoloration among four intervals with the same scaffold type regardless of the gender, age, and tooth location. The data were analyzed using Student's $t$ test and Chi-square test. The level of statistically significant difference was set at the confidence level of $95 \%$ and $p$ value $=0.05 . L^{*}, a^{*}$, and $b^{*}$ color factor's values were measured in five different periods (after treatment directly, after 3 months, after 6 months, after 9 months, and after 1 year) for each treated tooth in the sample. The human perceptibility threshold was set to 3.3 units to determine which differences were clinically visible. $\Delta E$ values were calculated, and clinical validity of $\Delta E$ was determined (unacceptable discoloration and acceptable discoloration). Then, the effects of the coronal barrier material and studied period on $\Delta E$ values and clinical validity of $\Delta E$ frequencies were studied, and the analysis results are shown in the Results section.

\section{$\triangle E$ Values Study}

Effect of coronal barrier material on $\Delta E$ values according to the studied period:

An independent sample $t$ test was applied to know if there were significant differences in $\Delta E$ values between MTA group and BC group according to the studied period as shown in Table 1. All $p$ values were greater than 0.05 . So, at the confidence level of $95 \%$, there were no significant differences in $\Delta E$ mean values between MTA group and BC group whatever the studied period was (after 3 months, after 6 months, after 9 months, and after 1 year) in the studied sample.

Effect of studied period on $\Delta E$ values according to the restorative material:

A paired sample $t$ test was applied to know if there were pairwise significant differences in $\Delta E$ values between the four studied periods (after 3 months, after 6 months, after 9 months, and after 1 year) according to the coronal barrier material as shown in Figure 5.

Paired sample $t$ test results (Table 2): 

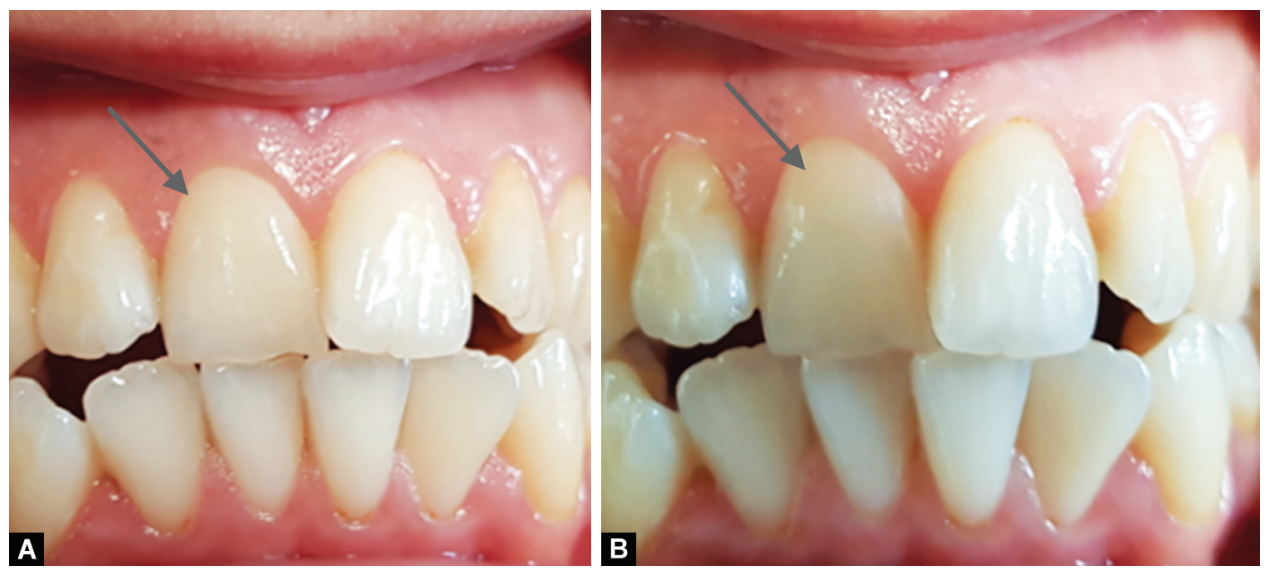

Figs 4A and B: Discoloration after application of bioceramic as a coronal barrier on the upper right central incisor: (A) After application directly; (B) After 6 months with preliminary discoloration

Table 1: Independent sample $t$ test results

\begin{tabular}{lllll}
\hline \multicolumn{5}{c}{ Studied variable $=\Delta E$} \\
\hline Studied period & $\begin{array}{l}\text { Mean } \\
\text { difference }\end{array}$ & $t$ & $p$ value & $\begin{array}{l}\text { Significant } \\
\text { difference }\end{array}$ \\
\hline After 3 months & 1.27 & 1.172 & 0.261 & No \\
After 6 months & 1.54 & 1.392 & 0.185 & No \\
After 9 months & 1.62 & 1.526 & 0.149 & No \\
After 1 year & 1.87 & 1.727 & 0.106 & No \\
\hline
\end{tabular}

The values of $p$ were greater than 0.05 when comparing $\Delta E$ values between after 6 months and after 9 months periods in the MTA group. So, at the confidence level of $95 \%$, there were no significant differences in $\Delta E$ values between after 6 months and after 9 months periods in the MTA group in the studied sample. All other $p$ values were lower than 0.05 . So, at the confidence level of $95 \%$, there were pair-wise significant differences in the corresponding mean values between the corresponding studied periods. Positive algebraic sign of mean differences indicates that statistically:

$\Delta E$ values after 6 months, after 9 months, and after 1 year were greater than those of after 3 months period whatever the studied coronal barrier material was.

$\Delta E$ values after 9 months and after 1 year values were greater than those of after 6 months whatever the studied restorative material was.

$\Delta E$ values after 1 year were greater than those of after 9 months whatever the studied restorative material was.

$\Delta E$ values for both materials increased statistically while studied period increased in the studied samples.

\section{Clinical Validity of $\triangle E$ Study}

Clinical validity of $\Delta E$ determination results according to coronal barrier material and studied period are shown in (Table 3 and Fig. 6).

Effect of coronal barrier material on clinical validity of $\Delta E$ according to the studied period:

An independent Chi-square test was applied to know if there were significant differences in clinical validity of $\Delta E$ frequencies between MTA group and BC group according to the studied period as shown in Table 4. All $p$ values were greater than 0.05 . So, at the confidence level of $95 \%$, there were no significant differences in clinical validity of $\triangle E$ frequencies between MTA group and BC group whatever the studied period was (after 3 months, after 6 months, after 9 months, and after 1 year) in the studied sample.

Effect of studied period on clinical validity of $\Delta E$ according to the coronal barrier material:

A Cochran's $Q$ test was applied to know if there were significant differences in clinical validity of $\Delta E$ frequencies between the four studied periods (after 3 months, after 6 months, after 9 months, and after 1 year) according to the coronal barrier material as shown in Figure 7.

\section{Cochran's Q Test Results}

Both $p$ values were greater than 0.05 (Table 5). So, at the confidence level of $95 \%$, there were no significant differences in clinical validity of $\Delta E$ frequencies between the four studied periods (after 3 months, after 6 months, after 9 months, and after 1 year) whatever the studied restorative material was (MTA group and BC group) in the studied sample.

\section{Results}

The average $\Delta E$ values according to the coronal barrier materials and studied period in each subgroup are shown in Table 6 and Figure 8.

The outcomes showed that discoloration after MTA application was above clinically perceptible threshold $(\Delta E>3.3)$ in all follow-up visits, whereas the coronal discoloration after 3.6 months of $B C$ use was below clinically perceptible threshold $(\Delta E<3.3)$ and then the discoloration increased slightly above clinically perceptible threshold $(\Delta E>3.3)$ after 9 and 12 months. The results revealed that considering the type of the coronal barrier material on crown discoloration was significantly higher in the MTA group compared with the BC group. However, no significant difference existed between MTA and BC groups $(p>0.05)$ at the confidence level of $95 \%$. Regarding the effect of intracanal scaffold "blood clot," the results showed that the type of coronal barrier (MTA or BC) had no significant effect on coronal discoloration $(p>0.05)$ whatever the studied period was. The reason beyond this result was although there was superiority of $\triangle E$ after MTA application rather than $\triangle E$ after $\mathrm{BC}$ application in all studied periods (Fig. 8), there was fairly a large standard deviation in both groups, especially in the MTA group, which relates to dispersion of values and huge disparity between minimum and maximum values in each group; for example, there is a large range between 1.71 and 9.56 in the MTA group and 1.28 and 5.69 in the BC group which led to the dispersion 


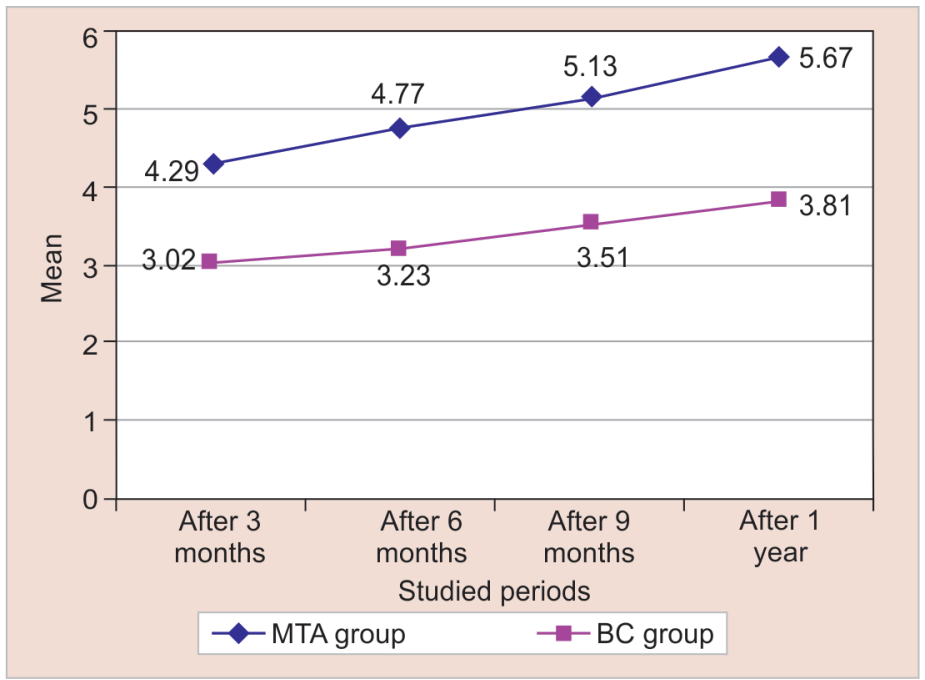

Fig. 5: Mean values of $\Delta E$ according to the studied period and coronal barrier material

Table 2: Paired sample $t$ test

\begin{tabular}{|c|c|c|c|c|c|}
\hline \multicolumn{6}{|c|}{ Studied variable $=\Delta E$} \\
\hline $\begin{array}{l}\text { Coronal barrier } \\
\text { material }\end{array}$ & Compared periods & Mean difference & $t$ & $p$ value & $\begin{array}{l}\text { Significant } \\
\text { difference }\end{array}$ \\
\hline \multirow[t]{6}{*}{ MTA group } & After 6 months and after 3 months & 0.48 & 3.202 & 0.015 & Yes \\
\hline & After 9 months and after 3 months & 0.85 & 3.063 & 0.018 & Yes \\
\hline & After 1 year and after 3 months & 1.38 & 4.982 & 0.002 & Yes \\
\hline & After 9 months and after 6 months & 0.37 & 2.153 & 0.068 & No \\
\hline & After 1 year and after 6 months & 0.91 & 5.383 & 0.001 & Yes \\
\hline & After 1 year and after 9 months & 0.54 & 4.832 & 0.002 & Yes \\
\hline \multirow[t]{6}{*}{$B C$ group } & After 6 months and after 3 months & 0.21 & 3.456 & 0.011 & Yes \\
\hline & After 9 months and after 3 months & 0.49 & 8.451 & 0.000 & Yes \\
\hline & After 1 year and after 3 months & 0.79 & 9.120 & 0.000 & Yes \\
\hline & After 9 months and after 6 months & 0.28 & 4.696 & 0.002 & Yes \\
\hline & After 1 year and after 6 months & 0.58 & 8.354 & 0.000 & Yes \\
\hline & After 1 year and after 9 months & 0.30 & 6.586 & 0.000 & Yes \\
\hline
\end{tabular}

Table 3: Clinical validity of $\Delta E$ frequencies

\begin{tabular}{|c|c|c|c|c|c|c|c|}
\hline \multirow[b]{2}{*}{ Studied period } & \multirow[b]{2}{*}{$\begin{array}{l}\text { Coronal barrier } \\
\text { material }\end{array}$} & \multicolumn{3}{|c|}{$n$} & \multicolumn{3}{|c|}{ Percentage } \\
\hline & & $\begin{array}{l}\text { Unacceptable } \\
\text { discoloration }\end{array}$ & $\begin{array}{l}\text { Acceptable } \\
\text { discoloration }\end{array}$ & Total & $\begin{array}{l}\text { Unacceptable } \\
\text { discoloration }\end{array}$ & $\begin{array}{l}\text { Acceptable } \\
\text { discoloration }\end{array}$ & Total \\
\hline \multirow[t]{2}{*}{ After 3 months } & MTA group & 5 & 3 & 8 & 62.5 & 37.5 & 100 \\
\hline & BC group & 3 & 5 & 8 & 37.5 & 62.5 & 100 \\
\hline \multirow[t]{2}{*}{ After 6 months } & MTA group & 5 & 3 & 8 & 62.5 & 37.5 & 100 \\
\hline & $B C$ group & 3 & 5 & 8 & 37.5 & 62.5 & 100 \\
\hline \multirow[t]{2}{*}{ After 9 months } & MTA group & 6 & 2 & 8 & 75.0 & 25.0 & 100 \\
\hline & $B C$ group & 3 & 5 & 8 & 37.5 & 62.5 & 100 \\
\hline \multirow[t]{2}{*}{ After 1 year } & MTA group & 6 & 2 & 8 & 75.0 & 25.0 & 100 \\
\hline & BC group & 3 & 5 & 8 & 37.5 & 62.5 & 100 \\
\hline
\end{tabular}

of values. Although there was no significant difference between the studied materials, the type of the coronal barrier should be taken into consideration and its composition especially when in contact with blood which itself is considered as a discoloration causative factor, because the mean values of crown discoloration were higher in the MTA group compared with the BC group in all follow-up periods. In other words, the use of MTA as an internal coronal barrier after blood clot formation led to clear coronal discoloration which was more than the clinically noticeable value, whereas BC application led to slight coronal discoloration with lower level compared with MTA. There is no significant difference existed between 6 months and 9 months in the MTA group 


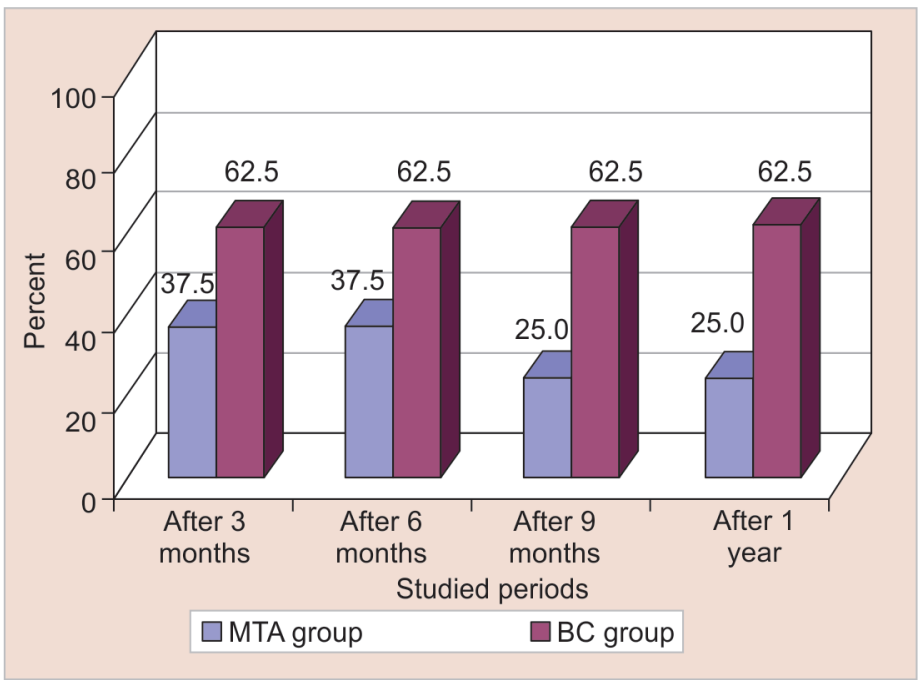

Fig. 6: Percentage of acceptable discoloration

Table 4: Chi-square test

\begin{tabular}{lllll}
\hline \multicolumn{5}{c}{ Studied variable $=\Delta E$} \\
\hline Studied period & $n$ & Chi-square & $p$ value & Significant difference \\
\hline After 3 months & 16 & 1.000 & 0.317 & No \\
After 6 months & 16 & 1.000 & 0.317 & No \\
After 9 months & 16 & 2.286 & 0.131 & No \\
After 1 year & 16 & 2.286 & 0.131 & No \\
\hline
\end{tabular}

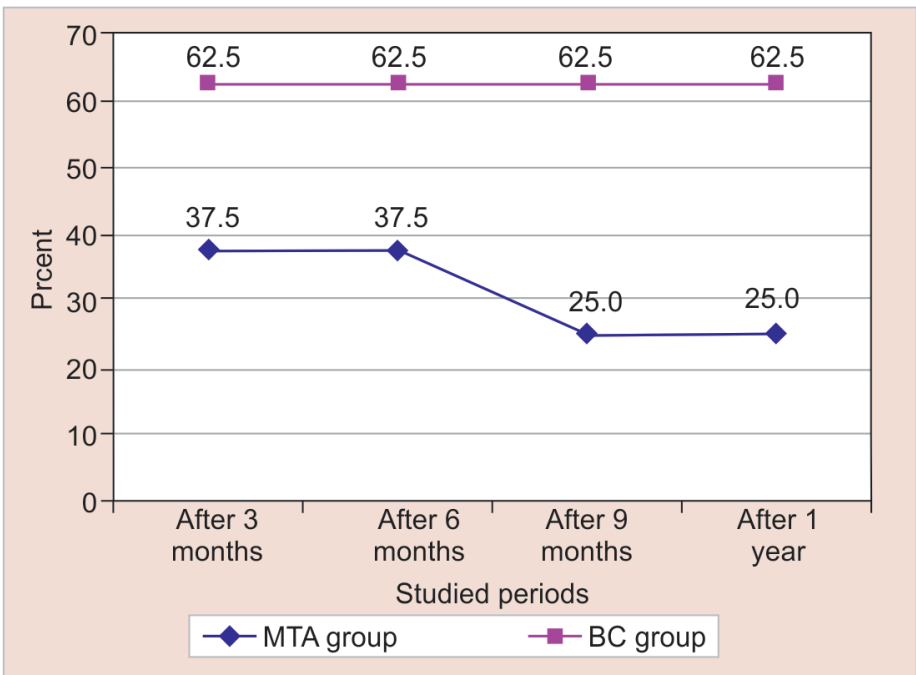

Fig. 7: Percentage of acceptable discoloration frequencies

Table 5: Cochran's $Q$ test results

\begin{tabular}{lllll}
\hline Coronal barrier material & $n$ & Cochran's $Q$ & $p$ value & Significant difference \\
\hline MTA group & 8 & 3.000 & 0.392 & No \\
BC group & 8 & 0 & 1.000 & No \\
\hline
\end{tabular}

$(p>0.05)$, whereas a significant difference existed between all other intervals in both MTA and BC groups, and therefore, the incremental increase in discoloration through sequential organized follow-up periods is clear.

\section{Discussion}

As the significant effect of discoloration is related to sodium hypochlorite with high concentrations in classic root canal therapy, ${ }^{12}$ as well as the AAE recommendations to avoid high concentrations 
Discoloration after Regenerative Endodontic Procedures

Table 6: $\Delta E$ descriptive statistics according to the coronal barrier material and studied period

\begin{tabular}{|c|c|c|c|c|c|c|c|}
\hline \multicolumn{8}{|c|}{ Studied variable $=\Delta E$} \\
\hline Studied period & $\begin{array}{l}\text { Coronal barrier } \\
\text { material }\end{array}$ & $n$ & Mean & $\begin{array}{l}\text { Standard } \\
\text { deviation }\end{array}$ & $\begin{array}{l}\text { Standard } \\
\text { error }\end{array}$ & Minimum & Maximum \\
\hline \multirow[t]{2}{*}{ After 3 months } & MTA group & 8 & 4.29 & 2.72 & 0.96 & 1.71 & 9.56 \\
\hline & $\mathrm{BC}$ group & 8 & 3.02 & 1.43 & 0.50 & 1.28 & 5.69 \\
\hline \multirow[t]{2}{*}{ After 6 months } & MTA group & 8 & 4.77 & 2.84 & 1.00 & 2.14 & 10.56 \\
\hline & BC group & 8 & 3.23 & 1.31 & 0.46 & 1.58 & 5.74 \\
\hline \multirow[t]{2}{*}{ After 9 months } & MTA group & 8 & 5.13 & 2.70 & 0.96 & 2.15 & 10.43 \\
\hline & BC group & 8 & 3.51 & 1.33 & 0.47 & 1.69 & 5.94 \\
\hline \multirow[t]{2}{*}{ After 1 year } & MTA group & 8 & 5.67 & 2.79 & 0.99 & 2.48 & 11.18 \\
\hline & BC group & 8 & 3.81 & 1.23 & 0.44 & 2.21 & 6.06 \\
\hline
\end{tabular}

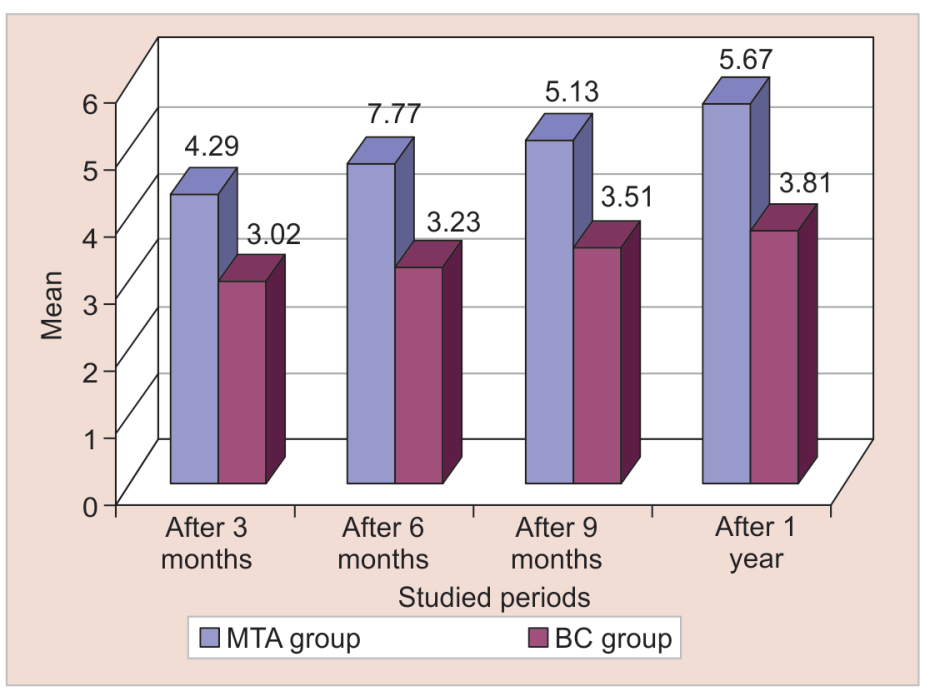

Fig. 8: Mean values of $\Delta E$ according to the coronal barrier material and studied period

of sodium hypochlorite in REPs to eliminate its toxic effect on stem cells in apical papilla, ${ }^{15}$ the $\mathrm{NaOCl}$ could be excluded from discoloration factors.

Within the limits of this study, which implicate study circumstances, patients behavior, and human error factor, discoloration is elicited by both coronal barrier materials accompanied by blood clot scaffold; so, the blood scaffold is accused to be the first responsible factor, and this could be explained by a previous explanatory mechanism. ${ }^{23,24}$ After hemolysis of erythrocytes from blood, the hemoglobin and hematin molecules may penetrate and accumulate in dentinal tubules, ${ }^{23,24}$ and while the closeness of the coronal third of the root to the cervical third of the crown, that might reflex the root discoloration onto the crown. ${ }^{25}$ Because of transition of $\mathrm{Fe}^{2+}$ (within red color) to $\mathrm{Fe}^{3+}$ (within dark brown color) in the center of heme group of blood through a natural redox reaction, and that could be the reason of discoloration of nearby root dentin, ${ }^{26}$ in addition to blood absorption into the fresh unsetting MTA which was located in the cervical region, by mechanism of iron ions releasing and interactions of calcium allumino ferrate embedded in porous calcium silicate materials which resorb pigmentary elements of blood ${ }^{9}$ and that may be secondary possible reason for discoloration. ${ }^{25}$

It has been shown that the discoloration is caused by blood contamination exacerbated with the use of calcium silicate materials which contain bismuth oxide (MTA), and the higher discoloration level could be attributed to color changes of coronal barriers itself which were located in contact with blood. ${ }^{9,17,26}$

The high bond strength of BC compared with MTA might be the preventive factor to limit leaking of the blood pigmentary elements into the dentin, where the premixed BC putty compared with separate powder and liquid for MTA and the thickening filler agents "zirconium oxide" added to BC to improve physical properties that make it as a putty form might also resulted in higher bond strength, ${ }^{27}$ and as this material has been developed with adhesion formation of tag-like structures inside the dentinal tubules as micromechanical bonding to dentin, ${ }^{28}$ all that could be the other possible reason to make discoloration with $\mathrm{BC}$ materials lower than that with MTA.

Either gray MTA or white MTA was attributed to perceptible crown discoloration, ${ }^{29,30}$ due to higher content of bismuth which is a radiopacifier agent. ${ }^{14}$ Nevertheless, the staining of teeth treated with white MTA was obvious in in vitro studies. ${ }^{31}$

Bismuth is linked to calcium silicate hydrate, then leaked, and decomposed from material, for this reason the discoloration would increase gradually with time, ${ }^{32}$ add to that the bismuth carbon complex; which resulting from interaction of bismuth oxide released from calcium silicate with carbon dioxide which suspected to be existed in blood clot during its setting. ${ }^{33}$

So, MTA itself is a doubtful factor that leads to teeth discoloration, and the results of this study affirmed that indeed, 
where most of the samples that underwent MTA exhibited higher color change compared with $\mathrm{BC}$ samples. The bismuth oxide molecule in MTA may be destabilized by amino acids in dentin collagen and that eventually lead to color change to black. ${ }^{34}$ Also, bismuth precipitates as dark sediment when it interacts with collagen especially after irrigation with EDTA which exposes collagen matrix of dentinal walls. ${ }^{35}$ Moreover, in this study, the pulp chamber walls were never sealed with DBA, which is a preventive step that could save tooth structure from bismuth migration and deny any more prospective discoloration. ${ }^{25}$

In the limitations of this study, BC was less involved in discoloration compared with MTA, and this result resembles the result of a previous study. ${ }^{31}$ Nevertheless, there was no significant differences between BC and MTA when in contact with blood, and this results agree with Shokouhinejad et al.'s study. ${ }^{17}$ Shokouhinejad et al. found that the type of coronal barrier materials (MTA or Biodentine) had no significant effect on coronal discoloration, whereas the type of the scaffold was considered as the responsible influential factor for discoloration, ${ }^{25}$ and the results agree to some extent with the present result.

An incremental increase in discoloration between sequential organized follow-up periods was observed in both groups, and this result is in accordance with a previous study $i^{10}$ however, the present result contradicts with Shokouhinejad et al.'s study which is based on DBA sealing of the pulp chamber and led to nonsignificant increase in discoloration till 6 months. ${ }^{25}$ The proposed limit for color difference was admitted at 3.3 in this study, whereas it was up to 3.7 in many other studies, ${ }^{10,30}$ and this difference may contribute to make lower discoloration values as a considerably perceptible value.

Generally, discoloration is a patient-oriented outcome, and there are many reasons implicated beyond it; starting from sodium hypochlorite, provisional medicament, scaffolds, and coronal barrier materials, add to that external factors such as patient's oral habits and level of oral care with regard to the nature of received nutrients. So it is not fair to impute this consequence for a single factor.

\section{CONCLUSION}

Under the conditions of this study, there is no significant difference between the discoloration following the application of MTA and BC RRM putty through follow-up intervals. Mineral trioxide aggregate could be used with caution, whereas BC RRM putty could be used as a preferable alternative material for sealing the coronal part of canal through REPs with the lowest discoloration possibility. Further (in vitro-ex vitro) studies are required to determine the most implicated reasons beyond discoloration in REPs to inhibit this unfavorable outcome.

\section{Clinical Significance}

Pulp REPs are predictable therapies, but discoloration is still considered one of the most unfavorable complications. So, this study highlights on this outcome to obviate it and utilize new suggested materials.

\section{References}

1. Hargreaves KM, Diogenes A, Teixeira FB. Treatment options: biological basis of regenerative endodontic procedures. J Endod 2013;39(3 Suppl):30-43. DOI: 10.1016/j.joen.2012.11.025.
2. Diogenes $A$, Ruparel NB, Shiloah Y, et al. Regenerative endodontics: a way forward. J Am Dent Assoc 2016;147(5):372-380. DOI: 10.1016/ j.adaj.2016.01.009.

3. Wigler R, Kaufman AY, Lin S, et al. Revascularization: a treatment for permanent teeth with necrotic pulp and incomplete root development. J Endod 2013;39(3):319-326. DOI: 10.1016/j.joen. 2012.11.014.

4. Shah N, Logani A. SealBio: a novel, non-obturation endodontic treatment based on concept of regeneration. J Conserv Dent 2012;15(4):328-332. DOI: 10.4103/0972-0707.101889.

5. Saoud TM, Martin G, Chen Y-HM, et al. Treatment of mature permanent teeth with necrotic pulps and apical periodontitis using regenerative endodontic procedures: a case series. J Endod 2016;42(1):57-65. DOI: 10.1016/j.joen.2015.09.015.

6. Kahler B, Rossi-Fedele G. A review of tooth discoloration after regenerative endodontic therapy. J Endod 2016;42(4):563-569. DOI: 10.1016/j.joen.2015.12.022.

7. Torabinejad M, Nosrat $A$, Verma $P$, et al. Regenerative endodontic treatment or mineral trioxide aggregate apical plug in teeth with necrotic pulps and open apices: a systematic review and meta-analysis. J Endod 2017;43(11):1806-1820. DOI: 10.1016/j.joen. 2017.06.029.

8. Reynolds K, Johnson JD, Cohenca N. Pulp revascularization of necrotic bilateral bicuspids using a modified novel technique to eliminate potential coronal discolouration: a case report. Int Endod J 2009;42(1):84-92. DOI: 10.1111/j.1365-2591.2008.01467.x.

9. Lenherr $\mathrm{P}$, Allgayer $\mathrm{N}$, Weiger $\mathrm{R}$, et al. Tooth discoloration induced by endodontic materials: a laboratory study. Int Endod J 2012;45(10): 942-949. DOI: 10.1111/j.1365-2591.2012.02053.x.

10. Akcay M, Arslan H, Yasa B, et al. Spectrophotometric analysis of crown discoloration induced by various antibiotic pastes used in revascularization. J Endod 2014;40(6):845-848. DOI: 10.1016/ j.joen.2013.09.019.

11. Asgary S, Parirokh M, Eghbal MJ, et al. Chemical differences between white and gray mineral trioxide aggregate. J Endod 2005;31(2): 101-103. DOI: 10.1097/01.don.0000133156.85164.b2.

12. Kontakiotis EG, Filippatos CG, Tzanetakis GN, et al. Regenerative endodontic therapy: a data analysis of clinical protocols. J Endod 2015;41(2):146-154. DOI: 10.1016/j.joen.2014.08.003.

13. Asgary S, Fazlyab M. A successful endodontic outcome with nonobturated canals. Iran Endod J 2015;10(3):208-210. DOI: 10.7508/ iej.2015.03.013.

14. Mozynska J, Metlerski M, Lipski M, et al. Tooth discoloration induced by different calcium silicate-based cements: a systematic review of in vitro studies. J Endod 2017;43(10):1593-1601. DOI: 10.1016/ j.joen.2017.04.002.

15. American Association of Endodontists. AAE Clinical Considerations for a Regenerative Procedure. Availableonline: https://www. aae.org/specialty/wpcontent/uploads/sites/2/2018/06/ ConsiderationsForRegEndo_AsOfApril2018.pdf (accessed on 1 April 2018).

16. Marin PD, Bartold PM, Heithersay GS. Tooth discoloration by blood: an in vitro histochemical study. Endod Dent Traumatol 1997;13(3): 132-138. DOI: 10.1111/j.1600-9657.1997.tb00026.x.

17. Shokouhinejad N, Nekoofar MH, Pirmoazen S, et al. Evaluation and comparison of occurrence of tooth discoloration after the application of various calcium silicate-based cements: an ex vivo study. J Endod 2016;42(1):140-144. DOI: 10.1016/j.joen.2015.08.034.

18. Akbari M, Rouhani A, Samiee S, et al. Effect of dentin bonding agent on the prevention of tooth discoloration produced by mineral trioxide aggregate. Int J Dent 2012. 563203. DOI: 10.1155/2012/563203.

19. Shokouhinejad N, Khoshkhounejad M, Alikhasi M, et al. Prevention of coronal discoloration induced by regenerative endodontic treatment in an ex vivo model. Clin Oral Investig 2018;22(4):1725-1731. DOI: 10.1007/s00784-017-2266-0.

20. Hargreaves KM, Berman LH. Cohen's pathways of the pulp. 11th ed., St. Louis: Mosby Elsevier; 2016. pp. 447-473. 
21. Sakaguchi RL, Powers JM. Craig's Restorative dental materials. 13th ed., St Louis: Elsevier Mosby; 2012. pp. 55-57.

22. Marconyak LJJr, Kirkpatrick TC, Roberts HW, et al. A comparison of coronal tooth discoloration elicited by various endodontic reparative materials. J Endod 2016;42(3):470-473. DOI: 10.1016/ j.joen.2015.10.013.

23. Marin PD, Heithersay GS, Bridges TE. A quantitative comparison of traditional and non-peroxide bleaching agents. Endod Dent Traumatol 1998;14(2):64-67. DOI: 10.1111/j.1600-9657.1998.tb00811.x.

24. Felman D, Parashos P. Coronal tooth discoloration and white mineral trioxide aggregate. J Endod 2013;39(4):484-487. DOI: 10.1016/ j.joen.2012.11.053.

25. Shokouhinejad N, Razmi H, Farbod M, et al. Coronal tooth discoloration induced by regenerative endodontic treatment using different scaffolds and intracanal coronal barriers: a 6-month ex vivo study. Restor Dent Endod 2019;44(3):e25. DOI: 10.5395/rde.2019.44. e25.

26. Guimarães BM, Tartari T, Marciano MA, et al. Color stability, radiopacity, and chemical characteristics of white mineral trioxide aggregate associated with 2 different vehicles in contact with blood. J Endod 2015;41(6):947-952. DOI: 10.1016/j.joen.2015.02.008.

27. Shokouhinejad N, Razmi H, Nekoofar M, et al. Push-out bond strength of bioceramic materials in a synthetic tissue fluid. J Dent 2013;10:540-547.

28. Wang Z. Bioceramic materials in endodontics. Endod Topics 2015;32(1):3-30. DOI: 10.1111/etp.12075.
29. Chen MYH, Chen KL, Chen CA, et al. Responses of immature permanent teeth with infected necrotic pulp tissue and apical periodontitis/abscess to revascularization procedures. Int Endod J 2012;45(3):294-305. DOI: 10.1111/j.1365-2591.2011.01978.x.

30. Ioannidis K, Mistakidis I, Beltes $\mathrm{P}$, et al. Spectrophotometric analysis of coronal discolouration induced by grey and white MTA. Int Endod J 2013;46(2):137-144. DOI: 10.1111/j.1365-2591.2012.02098.x.

31. Kohli MR, Yamaguchi M, Setzer FC, et al. Spectrophotometric analysis of coronal tooth discoloration induced by various bioceramic cements and other endodontic materials. J Endod 2015;41(11): 1862-1866. DOI: 10.1016/j.joen.2015.07.003.

32. Camilleri J. Characterization of hydration products of mineral trioxide aggregate. Int Endod J 2008;41(5):408-417. DOI: 10.1111/j.13652591.2007.01370.x.

33. Kang SH, Shin YS, Lee HS, et al. Color changes of teeth after treatment with various mineral trioxide aggregate-based materials: an ex vivo study. J Endod 2015;41(5):737-741. DOI: 10.1016/j.joen.2015. 01.019 .

34. Marciano MA, Costa RM, Camilleri J, et al. Assessment of color stability of white mineral trioxide aggregate angelus and bismuth oxide in contact with tooth structure. J Endod 2014;40(8):1235-1240. DOI: 10.1016/j.joen.2014.01.044.

35. Marciano MA, Duarte MA, Camilleri J. Dental discoloration caused by bismuth oxide in MTA in the presence of sodium hypochlorite. Clin Oral Investig 2015;19(9):2201-2209. DOI: 10.1007/s00784-0151466-8. 